\title{
Research on Structured Description Framework of High Temperature Molten Metal Accident
}

\author{
Tan YANG ${ }^{1,2}$, Qixing $\mathrm{ZHANG}^{{ }^{*}}$, Xunxian $\mathrm{SHI}^{3}$, Yongming ZHANG ${ }^{\mathbf{1}}$ \\ ${ }^{I}$ State Key Laboratory of Fire Science, University of Science and Technology of China, Hefei 230026, \\ China \\ ${ }^{2}$ Key Laboratory of Building Structure of Anhui Higher Education Institute, Anhui Xinhua University, \\ Hefei, 230088, China \\ ${ }^{3}$ China academy of safety science and technology, Beijing 100000, China \\ *Corresponding Author.
}

\begin{abstract}
The high-temperature molten metal leakage accident and its secondary accidents have become urgent problems to be solved in the current metallurgical industry because of their destructive power. The description of the high temperature molten metal leakage accident structure is the basis for studying its evolution law. Based on the idea of collection, this article uses multiple case analysis methods to abstract the accident attributes, and constructs an accident institutionalized description framework with the content of accident types, internal attributes, environmental attributes, management attributes, and hazard assessment attributes. A structured description of the leak. Finally, the "4.18" ladle capping accident of Qinghe special steel in Tieling, Liaoning Province was selected for example verification, and the attribute relationship between the primary accident and the secondary accident was analyzed. The research results have reference value for studying the evolution law of high temperature molten metal leakage accidents and making emergency decisions.
\end{abstract}

Keywords: High temperature molten metal leakage accident, Multiple case studies, Collection; Structured description, Event attributes

\section{Introduction}

With the rapid development of China's national economy, metallurgical industry has gradually become an important accelerator to promote economic development. Due to the wide range of products involved in the metallurgical industry, complex processes, large production equipment, high production temperatures, many toxic and hazardous substances, and long operating cycles, etc, The safety problem is more prominent in its production process ${ }^{[1]}$. For example, in 2012, a splash accident at the Anshan Cast Steel Plant caused 13 deaths and 17 injuries; in 2012, the Baosteel Steel Plant "12 • 17" ladle overturning accident caused 3 deaths and 17 injuries; 2014 In Nujiang Dingsheng Smelting and Chemical Co., Ltd., a high-temperature molten metal explosion occurred in water, killing 4 people and injuring 8 people ${ }^{[2]}$. Metallurgical accidents have caused huge losses to enterprises and society, greatly threatening the safety of people's lives and property and the harmony and stability of society. Therefore, understanding the metallurgical accidents, mastering their development and evolution laws, and reducing the losses caused by accidents by reducing the probability of accidents or by strengthening preventive measures are the issues that the metallurgical industry urgently needs to solve.

Scholars at home and abroad have done a lot of application research on metallurgical accidents. From the analysis of available data, it is known that the current research work is mainly focused on the dynamic evolution of accidents such as fire and explosion, leakage of toxic and harmful gases, leakage and spread of dangerous chemicals, and prediction of consequences However, the structural description of high temperature molten metal accidents has not been reported in the literature. Judging from the logic procedure of accident handling, the depth

ISSN: 0010-8189

(C) CONVERTER 2020

www.converter-magazine.info 
of accident understanding directly determines the direction of accident evolution and the choice of accident handling methods. Therefore, research on the structural description of high temperature molten metal accidents is an important basis for responding to molten metal accidents, formulating accident response strategies, and performing accident control, and has great significance for controlling the evolution progress of accidents and making accurate emergency decision-making.

According to the characteristics of the research content of this paper, a descriptive case analysis is used to sort out and analyze the high-temperature molten metal leakage accidents. That is, the selected cases are described in accordance with the background, cause, process, and accident handling decisions of the accident. In the analysis process, the commonalities and differences between the accident causes are described through the analysis of the cause of the accident through the research case. The basic principles of case selection are as follows:

\section{Basis of research}

\subsection{Keywords of the study case}

According to the characteristics of the research content of this paper, a descriptive case analysis is used to sort out and analyze the high-temperature molten metal leakage accidents ${ }^{[3]}$. That is, the selected cases are described in accordance with the background, cause, process, and accident handling decisions of the accident. In the analysis process, the commonalities and differences between the accident causes are described through the analysis of the cause of the accident through the research case. The basic principles of case selection are as follows:

- Accident cases should be representative and able to reflect the common causes of high-temperature molten metal leakage accidents. The causes of high-temperature molten metal leakage accidents are complex, and it is difficult to distinguish them by a unified classification standard. However, according to the system safety engineering theory, the deep-seated causes of various accidents have a certain degree of convergence. When selecting accident cases, the commonality of the causes should be fully considered, and representative accident cases should be selected for analysis. Specifically, representative accident cases should generally meet the requirements of the high frequency of accidents on the one hand, and the scope of impact of the accident on the other hand. Wide and long-lasting influence.

- The accident case information should describe the accident process comprehensively and objectively. The comprehensive and objective information of accident cases can avoid subjective inferences in the analysis process to make up for the lack of information, which is essential for the structured description of accidents. Therefore, accident cases should be derived from statistical data distributed by authoritative organizations as much as possible, such as portal websites, statistical yearbooks, and scientific papers.

- The selected accident cases should be time-sensitive. In recent years, China's metallurgical industry has developed rapidly, and the scale of production and operation methods have also undergone tremendous changes. In addition, since 2016, China has carried out major industrial structural adjustments and upgrades to the metallurgical industry, which has caused great energy consumption, high pollution, Metallurgical enterprises with outdated production technology, environmental protection and safety production standards are restricted or eliminated, which has led to great progress in the production scale and operation level of metallurgical enterprises, and their safety production level has also improved. The causal factors in the past accident cases have decreased reference to the existing metallurgical enterprises' safety production.

\subsection{Collection}

A collection refers to a collective of concrete or abstract objects with a certain nature. Among them, the objects constituting the set are called the elements of the set ${ }^{[4]}$. The elements in the collection should have the characteristics of certainty, reciprocity and disorder. From the point of view of set theory, a high-temperature 
molten metal accident can be regarded as a series of accident-causing factors with a certain common attribute and different from each other. The common attribute refers to the nature of the causal factor and the inter-causing factor. The relationship is identical.

In summary, through case selection and analysis, the characteristics of high-temperature molten metal leakage accidents and their causative factors are analyzed, the common attributes among the causative factors are sought, and the high-temperature molten metal accidents are structured in a collective manner.

\section{Research methods and structured models}

\subsection{Selection of cases}

According to the basic principles of case selection in section 1.1, the '12.17' Shanghai Baosteel ladle tipping accident ${ }^{[5]}$, '2.20' Liaoning Anshan Cast Steel Plant's spray explosion accident ${ }^{[6]}$, and Liaoning Qinghe Special Steel's '4.18'ladle tipping accident ${ }^{[7]}$ were selected. There are 10 typical high-temperature molten metal leakage accidents. Due to space limitations, the article will not list information such as the accidents one by one.

\subsection{Case analysis and processing}

The selected accident case information are all from the Internet, including documents, news reports, pictures, and CNKI databases. The basic information processing ideas are: firstly, according to the accident development process to screen and sort accident information; secondly, sort the sorted information; finally, re-integrate the sorted information to build a structured description framework of the accident.

\subsection{Case analysis conclusion}

According to the results of accident case analysis, drawing lessons from system safety engineering ideas and set theory, the high-temperature molten metal leakage accident is regarded as a collection of multiple attributes such as humans, machines, rings, and pipes. Through the analysis of accident cases, the collection is detailed Translated into five structural modules: accident type, internal attributes, environmental attributes, management attributes, and hazard assessment attributes, the accident structured framework is as follows: High-temperature molten metal leakage accident $=\{\{$ accident type $\},\{$ internal property $\},\{$ environmental property $\},\{$ management property $\}$, $\{$ hazard assessment property $\}\}$, namely: Leak accident of metal solution $=\{\{$ Event type(ET) $\},\{$ Internal attribute(IA) $\},\{$ Environmental attribute(EA) $\},\{$ Management attribute(MA) $\},\{$ Hazard assessment attribute(HA) $\}\}$.

\section{Structured description of high-temperature molten metal leakage accident}

Based on the above structural framework of the high-temperature molten metal leakage accident, the following analysis is made for each structural module:

\subsection{Type of accident}

The elements of this structural module mainly describe the inherent attributes of the accident qualitatively. Research on accident classification at home and abroad is mainly carried out from the three perspectives of industry differences, injury processes or accident causes. High-temperature molten metal leakage accidents are obviously not suitable for classification according to industry differences. In addition, even if it is a similar accident, the injury process is subject to the safety of personnel. It is difficult to use uniform standards to classify accidents due to factors such as literacy, the availability of safety facilities, and the layout of the work site. From the analysis results of high-temperature molten metal leakage accidents over the years, it can be seen that the classification of accident types cannot be simply handled according to the cause of the accident. . For example, as a ladle tipping accident, there is a big difference between the ' 12.17 ' Shanghai Baosteel ladle tipping accident and

ISSN: 0010-8189 
the Liaoning Qinghe special steel '4.18' ladle tipping accident. The former is caused by the double plate hook falling off on one side and the rear It is the failure of the crane lifting the ladle. Therefore, in the classification of accident types, this article divides high-temperature molten metal leakage accidents into smelting accidents, transfer accidents and casting accidents according to the production process of high-temperature molten metal. This classification method combines accidents with specific production processes. On the one hand, it is beneficial to study the secondary derivative accidents of leakage accidents in different production links, and on the other hand, it can provide targeted suggestions on accident prevention in the production process.

\subsubsection{Leakage accidents in the smelting process}

The metal smelting system includes the blast furnace body, the iron casting yard in front of the furnace, the tuyere and above platforms, the top charging system, the hot blast stove, the crude gas dust removal system, the TRT residual pressure power generation system, the molten iron and slag transportation line, the slag processing system, and the coal Pulverized powder injection station, gas purification system and other equipment subsystems ${ }^{[8]}$. The smelting production process is shown in Figure 1.

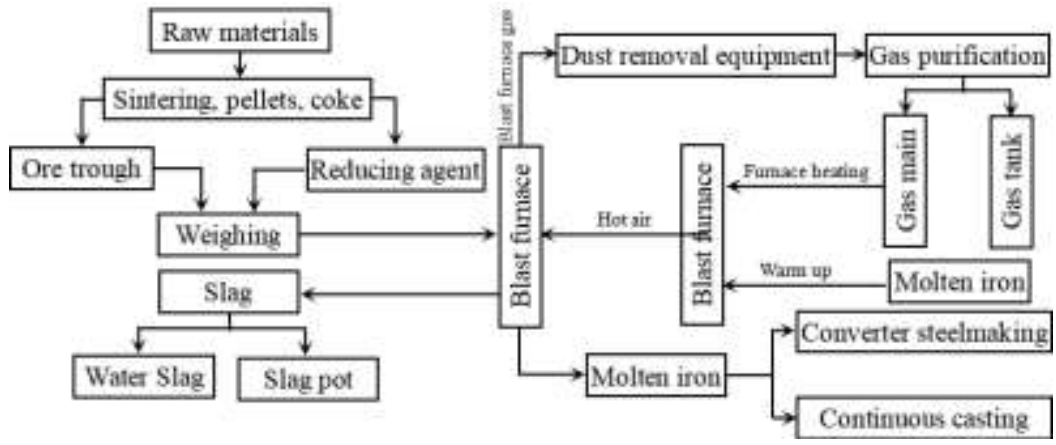

Fig 1: Schematic diagram of metal smelting process

The smelting production process is a continuous production process with high temperature, high pressure and concentration of toxic and hazardous gases. The types of hazardous and hazardous factors are complex and numerous, and the types of hazardous and hazardous factors in different subsystems vary greatly. According to the case analysis and summary, we can find that the high-temperature molten metal leakage accidents in the smelting production link are mainly concentrated in the blast furnace and the front of the furnace. The reason for the leakage in the furnace is the defect of the blast furnace equipment itself, and the molten iron is high in the furnace. Break down the furnace wall and flow out under the action; the leakage in the front of the furnace is mainly concentrated at the iron hole. The iron hole is too shallow, the quality of the mud gun in front of the furnace is poor, and the drill bit diameter of the opening machine is too large. Flow and other phenomena occur, and then molten iron leaks.

\subsubsection{Leakage accidents during transit}

The high-temperature molten metal transfer process is located after the smelting work. After the blast furnace is tapped, the molten iron ladle is transported to the pouring area through the transfer equipment. Generally, hightemperature molten metal transportation methods can be divided into four categories, namely, railway transportation, crane + straddle car transportation, special vehicle transportation, and "one-tank" transportation methods. During the transfer process, the ladle moves in the horizontal and vertical space, and there are major safety hazards. For example, the overflow of the molten steel tank, the falling or tipping of the molten metal ladle during the lifting process, etc., are the main causes of molten metal leakage accidents. One of the links. The main reasons for leakage accidents in the transfer link can be divided into three aspects. One is that the volume of the molten iron tank is too small, and overflow occurs when the volume of molten iron is large; the second is that the molten iron tank is unhooked and tipped during lifting; and the third is lifting. Inappropriate equipment selection or ill operation caused the molten iron ladle to fall during lifting.

\subsubsection{Leakage accidents in the casting process}

ISSN: 0010-8189

C CONVERTER 2020

www.converter-magazine.info 
In the high-temperature molten metal production operation, the casting operation is to cast the molten metal transferred from the converter into the specifications, shapes and sizes that meet the requirements of steel rolling and forging. ${ }^{[9]}$ The casting operation is a link between the smelting operation and the casting stage. At present, the casting process of most steel production enterprises in my country can be divided into two types: die casting and continuous casting. The die casting process is a process in which molten iron is formed in a steel ingot mold, which is mainly suitable for casting high carbon and high alloy steel and special specification steel; The continuous casting process is a process in which molten iron is continuously cast into billets through equipment such as rotary kilns, tundishes, crystallizers, and tension levelers, and is the most widely used. In the casting process, the hightemperature molten metal undergoes a phase change process from liquid to solid, accompanied by a large amount of heat release and molten steel splashing. Taking the continuous casting process (as shown in Figure 2) as an example ${ }^{[10][11]}$, the leakage points are mainly concentrated in Rotary furnace ladle dumping molten steel to the tundish link, ladle sliding nozzle failure, loss of control after the slide plate is opened, or abnormal flow of molten steel due to cracking of the ladle nozzle, etc. may cause molten steel to leak or overflow.

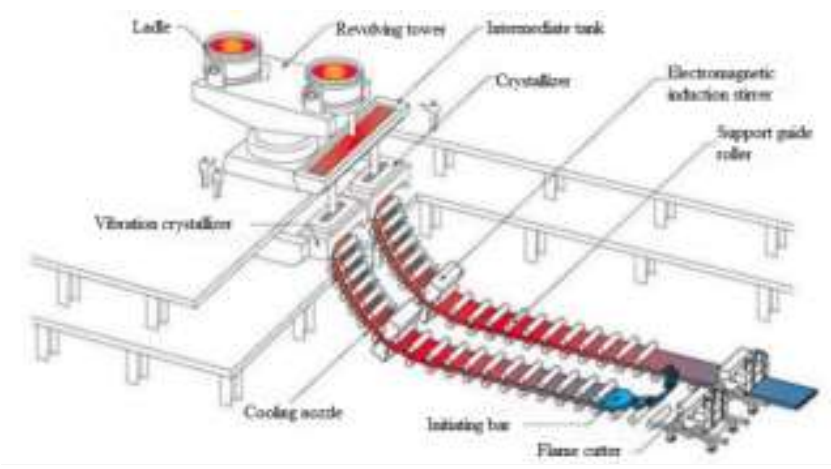

Figure 2: Schematic diagram of continuous casting process

\subsection{Internal attributes}

The effects of the elements contained in this structural module on accidents are mainly reflected in two aspects, namely, determining the severity of primary accidents and determining the evolution direction and degree of harm of secondary and derivative accidents. For high-temperature molten metal leakage accidents, the main elements that the structural module should contain are leakage volume, molten metal temperature and the location of the leakage point.

Regarding leakage accidents in the smelting process, whether it is a high-pressure breakdown in the furnace wall or a blast furnace taphole failure that causes the molten steel to leak, the occurrence process is a gradual process, and the amount of molten iron leakage is not large; the leakage is affected by the high temperature environment in the blast furnace. The temperature of molten steel is generally high; the leakage points are mainly concentrated in the iron hole in front of the furnace, which is relatively concentrated.

For leakage accidents in the transfer link, the hot metal leaks from the beginning of the blast furnace to the transfer to the continuous casting link, and there is always a hidden danger of leakage. Under different circumstances, the amount of leakage of the molten iron also varies greatly. After the blast furnace is tapped, the volume of the hot metal tank If it is too small, the amount of leakage caused by overflow is relatively small, but the amount of leakage caused by the decoupling and tipping or falling of the molten iron tank during the hoisting process is usually large, and it is also the most harmful in the high-temperature molten metal leakage accident; the temperature of the molten iron in the transfer process is relative to the blast furnace The internal temperature has dropped, but it is still in a relatively high temperature range; leakage points exist in all aspects of the transfer work, and the distribution is relatively scattered.

For leakage accidents in the pouring process, during the dumping of molten iron from the converter ladle to the ISSN: 0010-8189 
tundish, the molten iron leakage caused by the failure of the ladle sliding nozzle, the loss of control after the slide plate is opened, or the abnormal flow of molten steel due to the cracking of the ladle nozzle, is caused by the molten iron leakage in the ladle. There is no high pressure, which will not cause damage to the molten iron ladle tank. Therefore, the molten iron mainly leaks from the molten iron mouth, the leakage is not large, and the temperature is relatively lowest.

\subsection{Environmental attributes}

Environmental attributes are a comprehensive description of environmental conditions for high-temperature molten metal leakage and secondary accidents. Usually this module belongs to the external attributes of the accident and is weakly affected by the internal attributes of the accident, but it plays an important role in the severity of the accident and the direction of development and evolution influences. According to the analysis and summary of the accident, the environmental factors that affect the severity of the accident can be divided into the rationality of the layout of the workshop, the presence or absence of water in the site, and the presence of molten metal barrier measures. The environmental attributes of the high-temperature molten metal leakage accident are relatively easy to identify, but the boundary conditions are difficult to identify. Uniform determination can usually be determined according to national regulations, technical standards and related design documents.

Regarding leakage accidents in the smelting process, most of the molten metal leakage accidents occur at the iron hole in front of the furnace, which is caused by the abnormal flow of molten iron, especially during the shutdown and repair process, the molten metal penetrates the furnace wall and the connection position of the iron hole , Resulting in a large outflow of molten iron, at this time, the rationality of the main workshop layout that affects the severity of the accident. Taking the molten iron outflow accident of the Nanjing Iron and Steel Plant in Jiangsu in October 2011 as an example, in the work of slagging the No. 5 blast furnace, the residual molten iron in the blast furnace penetrated the furnace wall and gushed out. There was no implementation of blocking the molten iron outflow on site. Eventually lead to an accident.

For leakage accidents in the transfer link, the scope of molten metal leakage is more extensive, and the location of the leakage is more diverse. The factors that determine the direction of the accident, in addition to the rationality of the workshop layout, the value of on-site equipment, the distribution of personnel, and the molten metal barrier measures In addition to the evacuation capacity of evacuation channels, it also includes the distribution of process water in the site. Due to the large volume of molten metal leaked in the transfer process, the leaked molten iron will further evolve into secondary accidents such as explosions and splashes after being in contact with water during the ground flow process. For example, in April 2007, during a ladle fall accident in the production workshop of Tieling Qinghe Special Steel Co., Ltd., the shift meeting room was set within the scope of molten iron leakage, and the layout was unreasonable, which caused the ladle to be dumped directly at the color steel tile meeting after the fall. Above the room, 32 people were killed. In addition, the explosion accident caused by the contact between the flowing molten steel and the cooling water in the foundry further exacerbated the severity of the accident.

For leakage accidents in the pouring process, taking the continuous casting process as an example, the volume of molten metal leaking from the molten iron nozzle is small, and the leakage diffusion range is small, usually only causing damage to the casting equipment. At this time, the molten metal barrier measures are as follows: The main indicator that determines the severity of the accident.

\subsection{Management properties}

Management attributes are measures to identify, supervise and control the hazards that cause high-temperature molten metal leakage and secondary accidents. This module belongs to the control attribute of accidents, and mainly identifies and manages the internal attributes and environmental attributes of hazards that may cause accidents. Generally speaking, the elements that should be included in this module are mainly management system, ISSN: 0010-8189 
equipment management, personnel management, operating environment management and emergency drill management.

\subsection{Hazard assessment attributes}

The hazard assessment attribute is mainly for objects that may be damaged due to the occurrence of the accident. In the high-temperature molten metal leakage accident, the attribute mainly refers to the casualties and direct economic losses. These indicators are all external sources that are not highly dependent on the type of event. Attributes. Hazard assessment attributes are generally analyzed from two aspects: personnel distribution and field equipment value.

In the smelting workshop, the on-site personnel mainly include furnace managers, gun operators, alloy workers, furnace front workers, ladle turners and slag turners, etc., and the distribution of personnel is relatively concentrated. For leakage accidents in the smelting process, the leakage point is mainly at the blast furnace taphole. Therefore, the personnel near the taphole should be focused on in the analysis of personnel distribution. The value of on-site equipment should be converted according to the specific circumstances, including the replacement value of equipment, materials and safety protection facilities. Facilities that will not be damaged or need to be replaced (such as site leveling, underground pipelines and foundations, etc.) should be deducted during conversion.

The high-temperature molten metal in the transfer link has a long migration route, a wide range of leakage, and the location of the leakage point is relatively random. The distribution of on-site personnel is relatively scattered, and the personnel affected by the leakage also include those in the smelting workshop or casting workshop. In the hazard assessment The main consideration is the ability to evacuate personnel after the leak.

In the casting workshop, on-site personnel include captains, steel casting squad leaders, contract workers, fire cutters, general workers, and main controllers. Similar to the smelting workshop, the distribution of personnel in the casting workshop is also relatively concentrated. Due to the small leakage of high-temperature molten metal in the casting process, the evacuation capacity of personnel is the focus of the hazard assessment. In addition, the cooling process in the casting process requires a large amount of water, so it is necessary to prevent the molten metal from contacting water to cause explosions, splashing and other disasters.

\section{Methods and principles of accident attribute extraction}

\subsection{The method of accident attribute extraction}

After the construction of the accident descriptive framework is completed, how to use appropriate methods and principles to extract the attributes of the accident has become the key to further studying the evolution of accidents and formulating emergency response plans. Generally speaking, the structure of high-temperature molten metal leakage accidents is complex and is affected by the accident investigation procedure. The composition of accident attributes in specific accident cases is uncertain, so it is difficult to use quantitative analysis methods in the extraction of accident attributes., Relying on the professional knowledge and practical experience of experts, or using uncertainty analysis methods, such as rough sets.

\subsection{Basic principles of accident attribute extraction}

In order to extract accident attributes properly, a clearer extraction principle must be formulated for the extraction of accident attributes which is:

- The principle of seeking truth from facts

- System principle

- The whole area to be discussed should be determined, and the classification should be "neither repetition nor ISSN: 0010-8189

(C) CONVERTER 2020

Www.converter-magazine.info 
omission"

- In the same discussion, it can only be carried out according to one determined standard

- Multi-level discussions should be carried out level by level, without skipping levels

\section{Case analysis and verification}

According to the above description framework of high-temperature molten metal leakage accident, according to the accident attribute extraction and handling methods and basic principles, the structured framework description example verification of high-temperature molten metal leakage accident is carried out. At the same time, select the secondary accident of the high-temperature molten metal leakage accident (in this case, the splash accident analysis is selected) for structured description, and analyze the structural attributes between the primary accident (leak accident) and the secondary accident (splash accident). The relationship between the two provides ideas for explaining the evolution law of high-temperature molten metal operation accidents.

6.1 Example verification of structured description framework for high-temperature molten metal leakage accidents

When verifying the structured description framework of high-temperature molten metal leakage accidents, specific historical accidents need to be sorted out, and combined with the content of the accident site investigation report, the accident analysis should be carried out objectively. Taking the "4.18" ladle overturning accident of Qinghe special steel in Tieling, Liaoning Province as an example, the structured framework can be described as: "4.18" ladle overturning and leakage accident $=\{$ transportation link leakage accident, $\{$ hot metal volume $30 \mathrm{t}$, hot metal temperature $1590^{\circ} \mathrm{C}$, leakage The location is above the ingot table $\}$, the transfer meeting room is within the scope of the molten iron ladle transfer, and there is no barrier measure for molten iron leakage on site $\}$, \{the illegal use of general bridge cranes instead of metallurgical cranes, process design is unreasonable, and on-site production management is chaotic $\},\{32$ people in the meeting room for the transfer of shifts $\}$.

6.2 Correlation analysis of leakage accident and its secondary accident attributes

After analyzing the other 9 historical accidents, it can be concluded that during the evolution of high-temperature molten metal leakage accidents, secondary accidents mainly include explosion accidents, fire accidents, splash accidents and burns. To characterize the above secondary disaster accidents, the results are shown in Figure 3 . It can be seen from Figure 3 that between the primary accident (leakage accident) and the secondary accident, the internal secondary accident is an accident chain formed by the correlation of different attributes of the accident description framework, which has an important reference for the study of accident evolution law value.

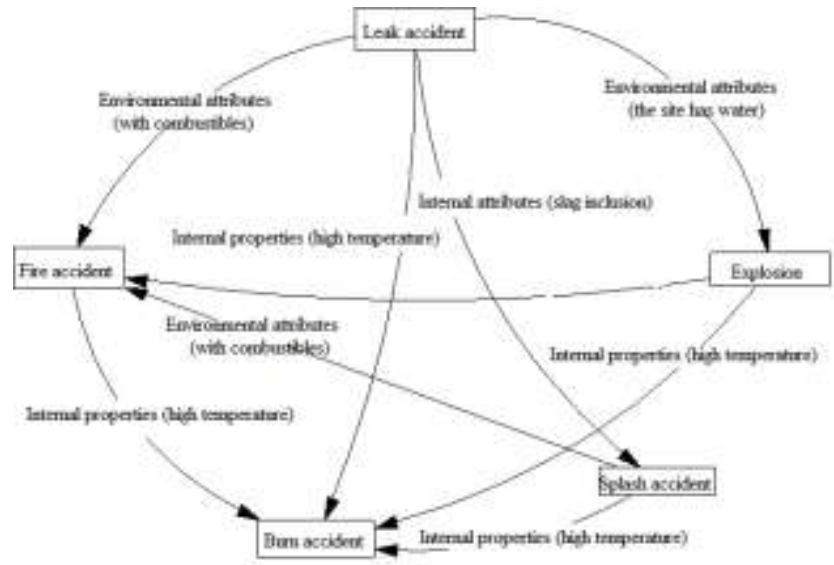

Figure 3: Schematic diagram of the correlation between leakage accidents and secondary accidents

6.3 Attribute correlation analysis of leakage accident and splash accident

ISSN: 0010-8189

(C) CONVERTER 2020

www.converter-magazine.info 
The secondary accident of the "4.18" ladle overturning and leakage accident of Qinghe Special Steel in Tieling, Liaoning (take the splash accident as an example) The structural frame can be described as: "4.18" ladle tipping and splashing accident $=\{$ transport link splashing accident, $\{$ Slag is trapped during the flow of molten steel, and the high temperature difference between molten steel and the ground $\},\{$ the evacuation exit layout is unreasonable, and there is water on the ground $\}$, \{the emergency evacuation plan is unreasonable, the on-site safety management is chaotic\}, \{operators are not wearing protective clothing\}\}. The attribute correlation between primary accidents and secondary accidents is shown in Figure 4. There is a one-to-one mapping relationship between the internal and environmental attributes of the leakage accident and the internal and environmental attributes of the secondary splash accident, that is, the temperature difference between the molten steel and the ground in the splash accident is higher due to the temperature of the molten iron in the leakage accident $1590^{\circ} \mathrm{C}$ (high temperature) decided that the unreasonable layout of evacuation exits in the splash accident was caused by the unreasonable setting of the shift meeting room in the leak accident, and the management attributes and hazard assessment attributes of the leak accident and the management attributes of the splash accident There is a many-to-one mapping relationship, that is, the unreasonable emergency evacuation plan in the splash accident is determined by the confusion of on-site production management in the spill accident, and the confusion of on-site safety management in the splash accident is caused by the concentration of personnel in the transfer conference room.

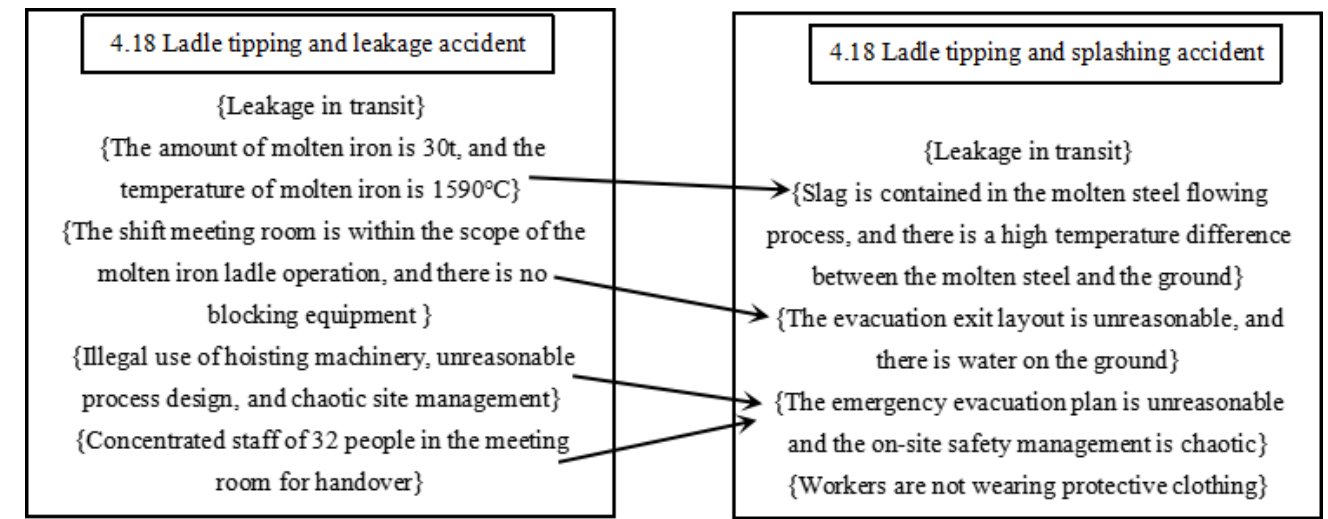

Figure 4: Schematic diagram of the correlation between the leakage accident and the splash accident attribute

\section{Conclusion}

The structure description of the high-temperature molten metal leakage accident is an important attempt to improve the understanding of the accident. This paper uses the set theory to study the structured description framework of the high-temperature molten metal leakage accident, which explains the combination of elements of the hightemperature molten metal leakage accident to a certain extent. Relationship, and the framework has been verified through the study of a number of historical accident cases. At the same time, primary accidents and secondary accidents are related to each other through the attributes contained in the framework, which has important guiding significance for studying the evolution direction of primary accidents and the choice of accident handling methods. However, it needs to be pointed out that the structured description model of high-temperature molten metal leakage accidents only uses 10 historical accident cases for verification. The extraction and definition of its frame attributes may have a certain degree of randomness, which still requires more accident cases verification. In addition, the research on the intrinsic motivation of the attribute correlation between primary accidents and secondary accidents and its influence on the evolution of accidents also needs to be improved through more historical accident data analysis.

\section{Acknowledgments}

This work was sponsored by the National Key Research and Development Plan under Grant NO.

ISSN: 0010-8189

(C) CONVERTER 2020

Www.converter-magazine.info 


\section{References}

[1] Y. Ke, Z. H. Deng. Historical review and prospect of the development of China's metallurgical industry. Journal of Wuhan University of Science and Technology (Social Science Edition), 2003(03): 39-43.

[2] Z. L. Du, H. L. Sun, A preliminary study on metallurgical safety issues and countermeasures in the metallurgical industry. China Metal Bulletin, 2018(06): 31+33.

[3] Y. J. Li, X. J. Qiao, X. C. Sun, Research on the structured description framework of emergencies. Journal of University of Electronic Science and Technology of China (Social Science Edition), 2013, 15(01): 28-33.

[4] M. H. Zhang, Case-based Unconventional Emergency Situational Reasoning Method Research. Wuhan: Huazhong University of Science and Technology, 2016.

[5] Zhang Le, Tong Xing. Safety nets and structural holes for daily risk management: A case analysis based on the August 12 accident in Tianjin Port. Social Science Research, 2019(05): 119-128.

[6] Q. Wei. Safety analysis of common accidents in metallurgical enterprises [A]. Shanxi Metals Society, Hunan Metals Society, Henan Metals Society, etc. In 2014, 11 provinces (cities) Metals (Metallurgy) Society of Metallurgical Safety and Environmental Protection Academic Exchange Conference Proceedings. Shanxi Metals Society, Hunan Metals Society, Henan Metals Society, etc.: Shanxi Metals Society, 2014: 5.

[7] T. Yang, Q. X. Zhang, Y. M. Zhang and T. Y. Wu, Safety Status Evaluation of Mixing Furnace in Aluminum Foundry Based on D-S Evidence Theory-Normal Membership. The Hong Kong Polytechnic University, Xi'an Jiaotong-Liverpool University, National Cheng Kung University, etc. ICUEMS 2020 Conference Proceedings.IEEE, 2020, 04: 613-617.

[8] Vairo. Tomaso, Pontiggia. Marco, Fabiano. Bruno, Critical aspects of natural gas pipelines risk assessments. A case-study application on buried layout. Process Safety and Environmental Protection, $2021,149$.

[9] J. Zhang, H. F. Bian, H. H. Zhao, X. X. Wang, L. L. Zhang, Y. P. Bai, Bayesian Network-Based Risk Assessment of Single-Phase Grounding Accidents of Power Transmission Lines. International Journal of Environmental Research and Public Health, 2020, 17(6).

[10] X. P. Duan, J. T. Han, The root causes and countermeasures of frequent metallurgical safety production accidents. Metallurgical Management, 2021(05): 178-179.

[11] F. D. Zhang, The root causes and countermeasures of frequent metallurgical safety production accidents. Metallurgical Economics and Management, 2012(06): 36-37. 